\title{
Association between dietary phyto- oestrogens and bone density in men and postmenopausal women
}

Article

Published Version

Kuhnle, G. G. C., Ward, H. A., Vogiatzoglou, A., Luben, R. N., Mulligan, A., Wareham, N. J., Forouhi, N. G. and Khaw, K.-T. (2011) Association between dietary phyto-oestrogens and bone density in men and postmenopausal women. British Journal of Nutrition, 106 (7). pp. 1063-1069. ISSN 0007-1145 doi: https://doi.org/10.1017/S0007114511001309 Available at https://centaur.reading.ac.uk/20335/

It is advisable to refer to the publisher's version if you intend to cite from the work. See Guidance on citing.

To link to this article DOI: http://dx.doi.org/10.1017/S0007114511001309

Publisher: Cambridge University Press

All outputs in CentAUR are protected by Intellectual Property Rights law, including copyright law. Copyright and IPR is retained by the creators or other copyright holders. Terms and conditions for use of this material are defined in the End User Agreement. 


\section{CentAUR}

Central Archive at the University of Reading

Reading's research outputs online 


\title{
Association between dietary phyto-oestrogens and bone density in men and postmenopausal women
}

\author{
Gunter G. C. Kuhnle ${ }^{1,2,3 *}$, Heather A. Ward ${ }^{2}$, Anna Vogiatzoglou ${ }^{1}$, Robert N. Luben ${ }^{2}$, Angela Mulligan², \\ Nicholas J. Wareham ${ }^{3}$, Nita G. Forouhi ${ }^{3}$ and Kay-Tee Khaw ${ }^{2}$ \\ ${ }^{1}$ Department of Food and Nutritional Sciences, University of Reading, Whiteknights, PO Box 226, Reading RG6 6AP, UK \\ ${ }^{2}$ Strangeways Research Laboratory, Department of Public Health and Primary Care, Institute of Public Health, MRC Centre \\ for Nutritional Epidemiology in Cancer Prevention and Survival (CNC), University of Cambridge, Wort's Causeway, \\ Cambridge CB1 $8 R N$, UK \\ ${ }^{3}$ MRC Epidemiology Unit, Institute of Metabolic Science, Addenbrooke's Hospital, Hills Road, Cambridge CB2 OQQ, UK
}

(Received 20 September 2010 - Revised 8 February 2011 - Accepted 9 February 2011)

\section{Abstract}

Phyto-oestrogens have been associated with a decreased risk for osteoporosis, but results from intervention and observational studies in Western countries have been inconsistent. In the present study, we investigated the association between habitual phyto-oestrogen intake and broadband ultrasound attenuation (BUA) of the calcanaeum as a marker of bone density. We collected $7 \mathrm{~d}$ records of diet, medical history and demographic and anthropometric data from participants (aged 45-75 years) in the European Prospective Investigation into Cancer-Norfolk study. Phyto-oestrogen (biochanin A, daidzein, formononetin; genistein, glycitein; matairesinol; secoisolariciresinol; enterolactone; equol) intake was determined using a newly developed food composition database. Bone density was assessed using BUA of the calcanaeum. Associations between bone density and phyto-oestrogen intake were investigated in 2580 postmenopausal women who were not on hormone replacement therapy and 4973 men. Median intake of total phyto-oestrogens was 876 (interquartile range 412 ) $\mu \mathrm{g} / \mathrm{d}$ in postmenopausal women and 1212 (interquartile range 604) $\mathrm{gg} / \mathrm{d}$ in men. The non-soya isoflavones formononetin and biochanin A were marginally significant or significantly associated with BUA in postmenopausal women $(\beta=1 \cdot 2 ; P<0 \cdot 1)$ and men $(\beta=1 \cdot 2$; $P<0 \cdot 05)$, respectively; enterolignans and equol were positively associated with bone density in postmenopausal women, but this association became non-significant when dietary Ca was added to the model. In the lowest quintile of Ca intake, soya isoflavones were positively associated with bone density in postmenopausal women $(\beta=1 \cdot 4 ; P<0 \cdot 1)$. The present results therefore suggest that non-soya isoflavones are associated with bone density independent of $\mathrm{Ca}$, whereas the association with soya or soya isoflavones is affected by dietary Ca.

\section{Key words: Bone density: Phyto-oestrogens: Osteoporosis}

Dietary phyto-oestrogens have been associated with a decreased risk for osteoporosis because of their structural and functional similarities with $17 \beta$-oestradiol and their ability to interact with oestrogen receptors ${ }^{(1,2)}$, in particular oestrogen receptor- $\beta^{(3)}$. In vitro and animal studies have shown that phyto-oestrogens can modulate bone turnover and delay bone loss in acute oestrogen deficiency ${ }^{(4)}$. However, a meta-analysis of ten randomised clinical trials lasting at least 1 year found only a weak beneficial effect for larger doses of isoflavones $(>80 \mathrm{mg} / \mathrm{d})$, but none for lower doses ${ }^{(5)}$.

Observational studies have reported a positive association between phyto-oestrogen intake and bone density in Asian populations $^{(6,7)}$; however, studies in Caucasian populations are limited due to the lower habitual intake of phyto-oestrogens.
In the Shanghai Women's Health study of 75000 postmenopausal women, the median intake of soya isoflavones (genistein and daidzein) was $38 \mathrm{mg} / \mathrm{d}$, and there was a clear association between soya food consumption and a reduced risk for fractures $^{(6)}$. In contrast, the median intake of soya isoflavones in Caucasian women in the Study of Women's Health Across the Nation (SWAN) was $0.04 \mathrm{mg} / \mathrm{d}$, while in the same study, the intake among Chinese $(5.3 \mathrm{mg} / \mathrm{d})$ and Japanese $(18.9 \mathrm{mg} / \mathrm{d})$ women was much higher ${ }^{(7)}$.

We investigated the association between dietary phytooestrogens and bone density in 2580 women and 4973 men in the European Prospective Investigation into Cancer (EPIC)-Norfolk cohort ${ }^{(8)}$. In addition to soya isoflavones used in most observational studies conducted thus far, we have

Abbreviations: BUA, broadband ultrasound attenuation; DINER, Data into Nutrients for Epidemiological Research; EPIC, European Prospective Investigation into Cancer; SWAN, Study of Women's Health Across the Nation.

*Corresponding author: G. G. C. Kuhnle, fax + 44118931 0080, email g.g.kuhnle@reading.ac.uk 
also included lignans, enterolignans including equol and coumestrol in our analysis. To our knowledge, this is the largest observational study of the association between phyto-oestrogens and bone health conducted in a European population.

\section{Methods}

\section{Study population}

Between 1993 and 1997, approximately 25000 healthy men and women aged between 40 and 75 years were recruited for the EPIC-Norfolk study from general practitioners' databases $^{(8)}$. Health and lifestyle, including data on smoking, alcohol consumption, social class, family medical history, physical activity and reproductive history, were assessed by a questionnaire. Postmenopausal status was defined as at least twelve consecutive months of amenorrhoea. Height and weight measurements were collected following a standardised protocol as part of a health check conducted by research nurses ${ }^{(8)}$. Diet was assessed by a prospective $7 \mathrm{~d}$ diet diary at baseline. Between 1998 and 2000, men and women then aged 42-82 years were invited to attend a second visit, where quantitative ultrasound measurements of the calcaneum were conducted by trained research nurses, according to standardised protocols $(n \text { 10444) })^{(9-11)}$. Men $(n$ 4973) and postmenopausal women who were not on hormone replacement therapy
( $n$ 2897) were eligible for the present study. The study was approved by the Norwich District Health Authority Ethics Committee, and all participants gave signed informed consent.

\section{Analytical methods}

Diet was assessed at baseline with a $7 \mathrm{~d}$ diary using the inhouse dietary assessment software DINER (Data into Nutrients for Epidemiological Research) to calculate average daily nutrient intakes ${ }^{(12)}$. Dietary phyto-oestrogens were determined using the food composition database for foods commonly consumed in the $\mathrm{UK}^{(13-16)}$. More than 500 different foods were analysed by liquid chromatography-MS using ${ }^{13} \mathrm{C}$ labelled internal standards ${ }^{(13-17)}$; the limit of detection of this method was $1.5 \mathrm{~g} / 100 \mathrm{~g}$ dry weight (intra-batch CV was between 3 and 14\%; inter-batch CV was between 1 and $6 \%$ ). These data were used to calculate the phyto-oestrogens content of 10708 foods in DINER.

At the first follow-up visit (1998-2000), quantitative ultrasound was used to measure broadband ultrasound attenuation (BUA, dB/MHz) of the calcaneum. Using the CUBAClinical machine (McCue Ultrasonics, Winchester, UK), BUA was measured at least twice on each foot as described previously $^{(11)}$. A total of five machines were used, and each

Table 1. Descriptive characteristics of the study population at baseline: the European Prospective Investigation into Cancer-Norfolk study

(Mean values, standard deviations, medians and interquartile ranges)

\begin{tabular}{|c|c|c|c|c|}
\hline & \multicolumn{2}{|c|}{ Women $(n$ 2580) } & \multicolumn{2}{|c|}{ Men (n 4973) } \\
\hline & Median & Interquartile range & Median & Interquartile range \\
\hline \multicolumn{5}{|l|}{ Age (years) } \\
\hline Mean & & 65.9 & & $61 \cdot 3$ \\
\hline SD & & $5 \cdot 8$ & & 8.4 \\
\hline \multicolumn{5}{|l|}{ BMI $\left(\mathrm{kg} / \mathrm{m}^{2}\right)$} \\
\hline Mean & & $26 \cdot 5$ & & 26.5 \\
\hline SD & & $4 \cdot 2$ & & $3 \cdot 2$ \\
\hline \multicolumn{5}{|l|}{ Energy intake (MJ/d) } \\
\hline Mean & & $7 \cdot 0$ & & 9.5 \\
\hline SD & & 1.5 & & $2 \cdot 1$ \\
\hline \multicolumn{5}{|c|}{ Broadband ultrasound attenuation ( $\mathrm{dB} / \mathrm{MHz})$} \\
\hline Mean & & $64 \cdot 3$ & & 89.7 \\
\hline SD & & $15 \cdot 1$ & & $17 \cdot 6$ \\
\hline Ca intake $(\mathrm{mg} / \mathrm{d})$ & 743.4 & $601 \cdot 8-910 \cdot 2$ & $910 \cdot 4$ & $743 \cdot 8-1096 \cdot 2$ \\
\hline \multicolumn{5}{|l|}{ Nutrient intake $(\mu \mathrm{g} / \mathrm{d})$} \\
\hline Total phyto-oestrogens & $875 \cdot 7$ & $704 \cdot 8-1117 \cdot 2$ & $1212 \cdot 0$ & $954.0-1557.9$ \\
\hline Total isoflavones & $619 \cdot 8$ & $458 \cdot 1-836 \cdot 2$ & 875.5 & $643.5-1198.9$ \\
\hline Biochanin A & $16 \cdot 6$ & $12 \cdot 9-21 \cdot 7$ & 22.6 & $17 \cdot 1-29 \cdot 9$ \\
\hline Daidzein & 204.6 & $149 \cdot 5-277 \cdot 8$ & 289.4 & $209 \cdot 9-401 \cdot 1$ \\
\hline Formononetin & $2 \cdot 3$ & $1 \cdot 8-3.0$ & 3.4 & $2.5-4.9$ \\
\hline Genistein & 351.6 & $255 \cdot 1-480 \cdot 2$ & $497 \cdot 0$ & $359.9-684.4$ \\
\hline Glycitein & 40.9 & $30 \cdot 9-52 \cdot 7$ & 57.8 & $43 \cdot 7-74 \cdot 8$ \\
\hline Total lignans & $230 \cdot 0$ & $183.5-291.5$ & $287 \cdot 1$ & $220 \cdot 9-372.5$ \\
\hline Matairesinol & $35 \cdot 0$ & $27 \cdot 2-44 \cdot 0$ & 41.9 & $32 \cdot 2-53 \cdot 6$ \\
\hline Secoisolariciresinol & $193 \cdot 7$ & $151 \cdot 3-249.9$ & $242 \cdot 7$ & $182 \cdot 9-320 \cdot 8$ \\
\hline Coumestrol & 4.7 & $3 \cdot 2-7 \cdot 2$ & 5.7 & $3.9-8.6$ \\
\hline Total enterolignans and equol & $15 \cdot 6$ & $11 \cdot 6-20 \cdot 8$ & $18 \cdot 1$ & $13 \cdot 0-23 \cdot 8$ \\
\hline Enterodiol & 0.0 & $0.0-0.1$ & 0.0 & $0.0-0.1$ \\
\hline Enterolactone & $11 \cdot 8$ & $8 \cdot 7-15 \cdot 8$ & 13.5 & $9.9-17.9$ \\
\hline Equol & 3.8 & $2 \cdot 8-5 \cdot 0$ & 4.4 & $3 \cdot 2-5 \cdot 8$ \\
\hline
\end{tabular}


Table 2. Regression analysis of calcaneal broadband ultrasound attenuation (dB/MHz) and phyto-oestrogen intake (log transformed): the European Prospective Investigation into Cancer-Norfolk study

( $\beta$-Coefficients and $95 \%$ confidence intervals)

\begin{tabular}{|c|c|c|c|c|c|c|c|c|c|c|c|c|}
\hline & \multicolumn{6}{|c|}{ Women (n 2580) } & \multicolumn{6}{|c|}{ Men ( $n$ 4973) } \\
\hline & \multicolumn{3}{|c|}{ Multivariable model ${ }^{\star}$} & \multicolumn{3}{|c|}{ Multivariable model $+\mathrm{Ca}$} & \multicolumn{3}{|c|}{ Multivariable model ${ }^{\star}$} & \multicolumn{3}{|c|}{ Multivariable model $+\mathrm{Ca}$} \\
\hline & $\beta$ & $95 \% \mathrm{Cl}$ & $P$ & $\beta$ & $95 \% \mathrm{Cl}$ & $P$ & $\beta$ & $95 \% \mathrm{Cl}$ & $P$ & $\beta$ & $95 \% \mathrm{Cl}$ & $P$ \\
\hline Total phyto-oestrogens & 0.334 & $-0.707,1.375$ & 0.530 & 0.445 & $-0.596,1.487$ & 0.402 & 0.208 & $-0.786,1.203$ & 0.682 & 0.173 & $-0.821,1 \cdot 167$ & 0.732 \\
\hline Total isoflavones & 0.036 & $-0.795,0.866$ & 0.933 & 0.156 & $-0.676,0.988$ & 0.713 & 0.198 & $-0.612,1.008$ & 0.631 & $0 \cdot 160$ & $-0.650,0.970$ & 0.698 \\
\hline Biochanin A & 0.891 & $-0.443,2.225$ & 0.190 & 0.735 & $-0.601,2.070$ & 0.281 & 1.199 & $0 \cdot 140,2 \cdot 257$ & 0.026 & 1.176 & $0.118,2.233$ & 0.029 \\
\hline Formononetin & 1.212 & $-0.125,2.548$ & 0.076 & $1 \cdot 156$ & $-0.178,2.491$ & 0.089 & 0.764 & $-0.191,1 \cdot 718$ & 0.117 & 0.765 & $-0.189,1.719$ & 0.116 \\
\hline Daidzein & -0.018 & $-0.822,0.786$ & 0.965 & 0.093 & $-0.712,0.898$ & 0.821 & 0.270 & $-0.515,1.055$ & 0.500 & 0.218 & $-0.566,1.003$ & 0.586 \\
\hline Genistein & 0.016 & $-0.767,0.800$ & 0.967 & 0.134 & $-0.651,0.919$ & 0.737 & 0.191 & $-0.572,0.953$ & 0.624 & 0.156 & $-0.605,0.918$ & 0.687 \\
\hline Glycitein & -0.064 & $-1.089,0.961$ & 0.903 & 0.085 & $-0.943,1.113$ & 0.871 & -0.433 & $-1.462,0.596$ & 0.409 & -0.432 & $-1.460,0.596$ & 0.410 \\
\hline Coumestrol & 0.029 & $-0.825,0.883$ & 0.947 & -0.103 & $-0.959,0.753$ & 0.814 & 0.675 & $-0.147,1.497$ & 0.107 & 0.627 & $-0.195,1.448$ & 0.135 \\
\hline Lignans & 1.062 & $-0.381,2.505$ & 0.149 & 0.994 & $-0.447,2.436$ & 0.176 & 0.478 & $-0.735,1.692$ & 0.439 & 0.568 & $-0.646,1.781$ & 0.359 \\
\hline Matairesinol & -0.300 & $-1.667,1.067$ & 0.667 & -0.360 & $-1.725,1.005$ & 0.605 & -0.719 & $-1.908,0.469$ & 0.235 & -0.710 & $-1.897,0.478$ & 0.241 \\
\hline Secoisolariciresinol & 1.085 & $-0.272,2.441$ & 0.117 & 1.023 & $-0.331,2.378$ & 0.139 & 0.626 & $-0.510,1.761$ & 0.280 & 0.711 & $-0.425,1.847$ & 0.220 \\
\hline Total enterolignans and equol & 1.505 & $0.346,2.664$ & 0.011 & -0.033 & $-2.009,1.944$ & 0.974 & 0.160 & $-0.393,0.713$ & 0.570 & -0.293 & $-0.914,0.327$ & 0.354 \\
\hline Enterolactone & 1.424 & $0.311,2.537$ & 0.012 & -0.030 & $-1.879,1.819$ & 0.975 & 0.195 & $-0.355,0.745$ & 0.487 & -0.257 & $-0.876,0.363$ & 0.417 \\
\hline Equol & 1.523 & $0.367,2.680$ & 0.010 & 0.199 & $-1 \cdot 622,2 \cdot 021$ & 0.830 & 0.126 & $-0.444,0.696$ & 0.665 & -0.341 & $-0.978,0.296$ & 0.294 \\
\hline Cat & $3 \cdot 161$ & $1 \cdot 048,5 \cdot 274$ & 0.003 & - & - & - & 3.544 & $1.517,5.572$ & 0.001 & - & - & - \\
\hline
\end{tabular}

* Adjusted for age (years), BMI $\left(\mathrm{kg} / \mathrm{m}^{2}\right)$ and energy intake $(\mathrm{MJ} / \mathrm{d})$.

† Log transformed.

Table 3. Regression analysis of calcaneal broadband ultrasound attenuation ( $\mathrm{dB} / \mathrm{MHz})$ and phyto-oestrogen intake (log transformed), stratified by calcium intake*: the European Prospective Investigation into Cancer-Norfolk study

( $\beta$-Coefficients and $95 \%$ confidence intervals)

\begin{tabular}{|c|c|c|c|c|c|c|c|c|c|c|c|c|}
\hline & \multicolumn{6}{|c|}{ Women } & \multicolumn{6}{|c|}{ Men } \\
\hline & \multicolumn{3}{|c|}{ Low intake } & \multicolumn{3}{|c|}{ High intakef } & \multicolumn{3}{|c|}{ Low intake§ } & \multicolumn{3}{|c|}{ High intake\| } \\
\hline & $\beta$ & $95 \% \mathrm{Cl}$ & $P$ & $\beta$ & $95 \% \mathrm{Cl}$ & $P$ & $\beta$ & $95 \% \mathrm{Cl}$ & $P$ & $\beta$ & $95 \% \mathrm{Cl}$ & $P$ \\
\hline Total phyto-oestrogens & 1.829 & $-0.330,3.987$ & 0.097 & -0.274 & $-2 \cdot 647,2 \cdot 100$ & 0.821 & 0.121 & $-1.978,2.220$ & 0.910 & 0.089 & $-2.044,2.223$ & 0.935 \\
\hline Total isoflavones & 1.441 & $-0.269,3.151$ & 0.098 & -0.475 & $-2.375,1.424$ & 0.623 & 0.076 & $-1.623,1.774$ & 0.930 & 0.041 & $-1 \cdot 713,1 \cdot 796$ & 0.963 \\
\hline Biochanin A & 0.568 & $-2.201,3.338$ & 0.687 & 1.252 & $-1.948,4.451$ & 0.442 & $1 \cdot 131$ & $-0.928,3.190$ & 0.281 & -0.331 & $-2.717,2.055$ & 0.786 \\
\hline Formononetin & 1.082 & $-1.602,3.766$ & 0.429 & -0.947 & $-4.073,2 \cdot 180$ & 0.552 & -0.235 & $-2.094,1.624$ & 0.804 & 0.268 & $-1.982,2.519$ & 0.815 \\
\hline Daidzein & 1.388 & $-0.260,3.036$ & 0.099 & -0.486 & $-2 \cdot 325,1.354$ & 0.604 & 0.061 & $-1.563,1.686$ & 0.941 & 0.150 & $-1.551,1.851$ & 0.863 \\
\hline Genistein & 1.358 & $-0.263,2.979$ & $0 \cdot 100$ & -0.454 & $-2 \cdot 231,1.324$ & 0.616 & 0.178 & $-1.420,1.775$ & 0.827 & 0.009 & $-1.640,1.658$ & 0.991 \\
\hline Glycitein & 1.930 & $-0.125,3.985$ & 0.066 & $-1 \cdot 138$ & $-3.520,1.244$ & 0.348 & 0.286 & $-1.786,2.357$ & 0.787 & -0.909 & $-3.147,1.329$ & 0.426 \\
\hline Coumestrol & -0.641 & $-2.495,1.213$ & 0.497 & 0.580 & $-1.427,2.587$ & 0.570 & 0.970 & $-0.681,2.620$ & 0.249 & 0.851 & $-0.998,2.701$ & 0.366 \\
\hline Total lignans & 2.491 & $-0.875,5.857$ & 0.147 & 0.209 & $-2.991,3.409$ & 0.898 & 0.046 & $-2.373,2.465$ & 0.970 & 0.024 & $-2.681,2.729$ & 0.986 \\
\hline Matairesinol & 0.505 & $-2.513,3.523$ & 0.743 & 1.522 & $-1.766,4.809$ & 0.364 & 0.594 & $-1.776,2.964$ & 0.623 & -0.419 & $-3 \cdot 101,2 \cdot 262$ & 0.759 \\
\hline Secoisolariciresinol & 2.492 & $-0.665,5.648$ & 0.122 & -0.081 & $-3.054,2.892$ & 0.957 & 0.023 & $-2 \cdot 244,2 \cdot 290$ & 0.984 & 0.190 & $-2 \cdot 334,2 \cdot 713$ & 0.883 \\
\hline
\end{tabular}

* Adjusted for age (years), BMI $\left(\mathrm{kg} / \mathrm{m}^{2}\right)$ and energy intake $(\mathrm{MJ} / \mathrm{d})$.

$\dagger$ Bottom quintile $(198-570 \mathrm{mg} / \mathrm{d})$.

f Top quintle $(958-2363 \mathrm{mg} / \mathrm{d})$.

|| Top quintile $(1152-3251 \mathrm{mg} / \mathrm{d})$. 
Table 4. Age, energy intake, broadband ultrasound attenuation (BUA) and phyto-oestrogen intake in the top and bottom quintiles of calcuim intake in the European Prospective Investigation into Cancer-Norfolk study

(Medians and interquartile ranges)

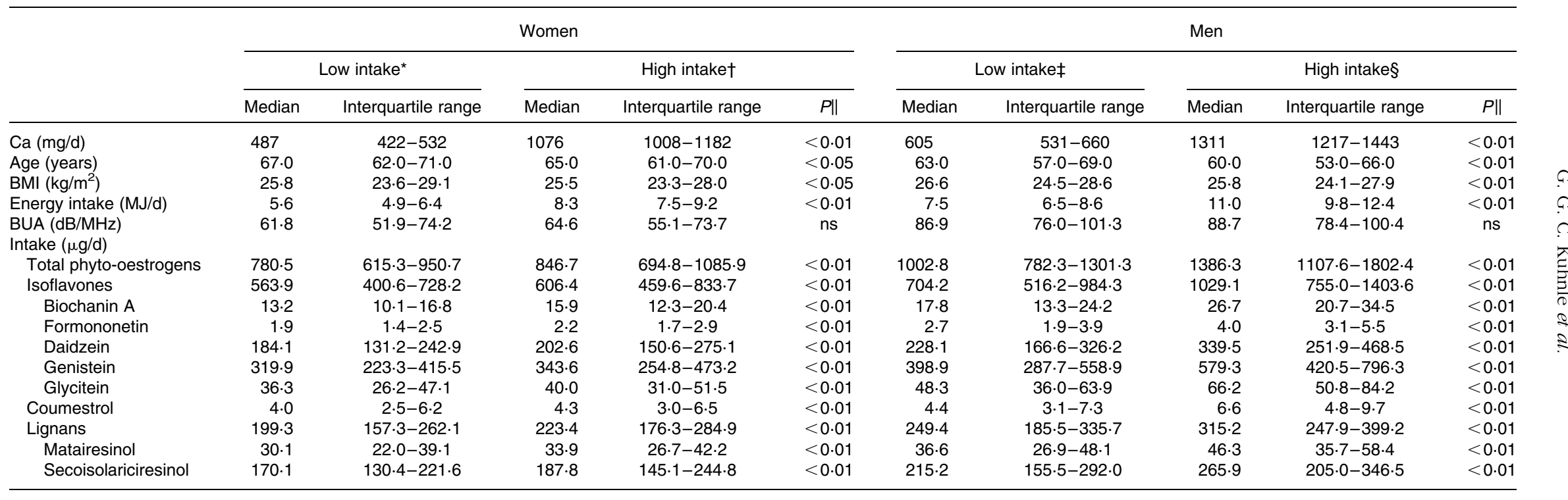

* Bottom quintile (198-570 mg/d).

† Top quintile $(958-2363 \mathrm{mg} / \mathrm{d})$.

† Bottom quintile $(161-699 \mathrm{mg} / \mathrm{d})$.

§ Top quintile $(1152-3251 \mathrm{mg} / \mathrm{d})$.

| Wilcoxon's rank-sum test. 
machine was calibrated daily with their physical phantom and monthly with a roving phantom and on one operator's calcaneum. As there was no effect of adjustments for temperature or machine, the data in the present study are presented unadjusted for temperature or machine ${ }^{(18)}$.

\section{Data analysis}

Descriptive characteristics of the study population were summarised using means and standard deviations for normally distributed continuous variables, frequency and percentages for categorical variables and medians (interquartile ranges) for non-normally distributed continuous variables. The bottom quintile of $\mathrm{Ca}$ intake was defined as 'low' intake (women 198-570 mg/d and men $161-699 \mathrm{mg} / \mathrm{d}$ ); the top quintile as 'high' intake (women $958-2363 \mathrm{mg} / \mathrm{d}$ and men $1152-3251 \mathrm{mg} / \mathrm{d})$.

Associations between BUA and log-transformed phytooestrogen intake were investigated using linear regression models, including age, BMI and total energy intake; potential confounders (age, BMI, energy intake and physical activity) were evaluated through comparison of models with and without the variable under examination, and were retained in the final model if their inclusion resulted in changes to the regression coefficient for total phyto-oestrogens intake of more than $10 \%$. For the regression analysis, dietary intake was log transformed. Dietary Ca and phyto-oestrogens were correlated using Spearman's rank correlation. Interactions between phyto-oestrogen intake and $\mathrm{Ca}$ intake were investigated by including an interaction term in the regression model. All analyses were conducted with STATA (version 10 for UNIX; Stata Corporation, College Station, TX, USA).

\section{Results}

BUA, anthropometric and dietary data were available for 4973 men and 2580 women who were postmenopausal and never on hormone replacement therapy. Table 1 shows demographic, anthropometric and dietary information of the study population. Median intake of phyto-oestrogens was lower in women $(0.9 \mathrm{mg} / \mathrm{d})$ than among men $(1.2 \mu \mathrm{g} / \mathrm{d})$. Among both sexes, the most common types of phyto-oestrogen were the isoflavones daidzein $(205 \mu \mathrm{g} / \mathrm{d}$ in women and $289 \mu \mathrm{g} / \mathrm{d}$ in men) and genistein $(352 \mu \mathrm{g} / \mathrm{d}$ in women and $497 \mu \mathrm{g} / \mathrm{d}$ in men), and the lignan secoisolariciresinol $(194 \mu \mathrm{g} / \mathrm{d}$ in women and $243 \mu \mathrm{g} / \mathrm{d}$ in men), with lower intakes in women than in men.

The results of the regression analyses are summarised in Table 2. In postmenopausal women, regression analyses with age, BMI and energy intake as covariables showed no significant association for total phyto-oestrogens, total isoflavones, coumestrol or lignans. Only formononetin showed a borderline significant positive association $(\beta=1 \cdot 2 ; P<0 \cdot 1)$, which remained significant when including dietary $\mathrm{Ca}$ in the model $(\beta=1 \cdot 2 ; P<0 \cdot 1)$. However, there was a significant association for total enterolignans and equol $(\beta=1.5$; $P<0.05)$, enterolactone $(\beta=1.4 ; \quad P<0.05)$ and equol $(\beta=1.5 ; P<0.05)$. When including dietary $\mathrm{Ca}$ as a covariable, these associations became non-significant. In men, only biochanin A was positively associated with BUA $(\beta=1 \cdot 2$; $P<0.05)$, and this association remained significant when including dietary $\mathrm{Ca}$ in the model $(\beta=1 \cdot 2 ; P<0 \cdot 02)$. Dietary $\mathrm{Ca}$ was significantly associated with BUA in women $(\beta=3.2 ; P<0.005)$ and men $(\beta=3.5 ; P<0.005)$, and it was significantly correlated with enterolactone and equol intake (Spearman's $r$ 0.88, $P<0.001$ in men; 0.90, $P<0.001$ in women).

Formal tests for interaction between $\mathrm{Ca}$ and phyto-oestrogen intake were conducted but showed no significant result. Following stratification of data by Ca intake, a borderline significant association was found in women between BUA and the intake of total phyto-oestrogens $(\beta=1 \cdot 8 ; P<0 \cdot 1)$ and isoflavones $(\beta=1 \cdot 4 ; P<0 \cdot 1)$, in particular the soya isoflavones daidzein $(\beta=1.4 ; P<0 \cdot 1)$, genistein $(\beta=1.4 ; \quad P<0 \cdot 1)$ and glycitein $(\beta=1.9 ; P<0 \cdot 1)$ in the lowest quintile of $\mathrm{Ca}$ intake (Table 3). No significant association was found in the highest quintile and in men. BUA was not significantly different between the highest and lowest quintiles of $\mathrm{Ca}$ intake (Table 4); however, participants in the lowest quintile were significantly older and had a higher BMI, but consumed a lower amount of phyto-oestrogens.

\section{Discussion}

The present investigation of phyto-oestrogen intake and bone density is the largest prospective study in a Western population undertaken so far. The EPIC-Norfolk cohort was well positioned to investigate the associations between dietary phyto-oestrogens and bone density in a Western population and to improve the observational data available. Whereas most studies conducted previously have investigated only the effect of the so-called soya isoflavones daidzein and genistein $^{(19)}$, the present study also included other isoflavones and other types of phyto-oestrogens such as lignans, coumestrol, enterolignans and equol using data from a newly developed food composition database ${ }^{(20)}$. A further strength of the present study is the use of $7 \mathrm{~d}$ food diaries. However, a limitation of the study is that only information for two types of lignans, matairesinol and secoisolariciresinol, are available. A further limitation of the present study, as with other studies relying on dietary data to assess exposure to phyto-oestrogens, is that inter-individual differences in metabolism, in particular the conversion of phyto-oestrogens to equol, $O$-desmethylangolensin and enterolignans by the intestinal microflora, cannot be accounted for. In the present study, we used BUA instead of dual-energy X-ray absorptiometry (DXA); quantitative ultrasound or BUA has been identified as a reliable and accurate tool for the assessment of osteoporosis and fracture risk. A recent comparison has shown that quantitative ultrasound is at least as reliable as DXA for the prediction of fractures in the elderly ${ }^{(21,22)}$.

Compared with the dietary intake of genistein and daidzein in other observational studies, the median intake in women of the EPIC-Norfolk cohort was higher than in European women in the SWAN study $(0.6 v .0 .04 \mathrm{mg} / \mathrm{d})$ and cohorts in The Netherlands $\left(0.4 \mathrm{mg} / \mathrm{d}^{(23)}\right)$ and Canada $\left(0.2 \mathrm{mg} / \mathrm{d}^{(24)}\right)$, 
but lower than in a Californian cohort $\left(1.7 \mathrm{mg} / \mathrm{d}^{(25)}\right)$ and much lower than in Japanese $(7.2 \mathrm{mg} / \mathrm{d})$ or Chinese $(3.5 \mathrm{mg} / \mathrm{d})$ participants of the SWAN study ${ }^{(7)}$ or in the Shanghai Women's Health Study $\left(38.0 \mathrm{mg} / \mathrm{d}^{(6)}\right)$.

Significant or borderline significant positive associations between dietary phyto-oestrogens and bone density measured as BUA were only found for the non-soya isoflavones formononetin in women and biochanin A in men; high amounts of these compounds are found, for example, in chick peas ${ }^{(16)}$. Formononetin and biochanin A are both $3^{\prime}$-methylated isoflavonoids, which differ only in the presence of an hydroxyl group in the $5^{\prime}$-position; however, it is not possible to investigate whether this structural difference explains the observed associations with the data available.

There was no significant association between any lignan and bone density. Although the coumestan coumestrol was the first phyto-oestrogen for which animal studies have suggested a protective effect on bones ${ }^{(26)}$, no significant effect was found in the present study.

Strong significant associations were observed for the socalled 'mammalian phyto-oestrogens', enterolactone and equol, in postmenopausal women, but not in men. These compounds are formed from lignans and daidzein, respectively, by the gastrointestinal microflora ${ }^{(27)}$. So far, it has not been possible to investigate the associations between these compounds and bone density directly, as insufficient information on the dietary content of these compounds was available.

Dietary Ca is an important contributor to bone health ${ }^{(28,29)}$ and positively associated with bone density. We have therefore investigated the effect of dietary $\mathrm{Ca}$ on the associations observed. Whereas no significant effect was observed for phyto-oestrogens of plant origin, the associations between BUA and enterolignans and equol in postmenopausal women were attenuated and became non-significant. The main sources of enterolignans and equol in the diet of participants of the EPIC-Norfolk study are cheese and other dairy products $^{(13)}$, which are also a main source of $\mathrm{Ca}$, and the strong correlation between these compounds and dietary $\mathrm{Ca}$ is a possible explanation. The high correlation limits our ability to identify which dietary factor exerted greater influence, and it is possible that enterolignan and equol intake does affect bone density but is attenuated on adjustment for dietary $\mathrm{Ca}$ as a result of collinearity.

We have further investigated the effect of Ca by stratifying the cohort by $\mathrm{Ca}$ intake: in the lowest quintile of Ca intake (less than $570 \mathrm{mg} / \mathrm{d}$ ) in postmenopausal women, total phytooestrogens, total isoflavones and soya isoflavones were all positively associated with BUA, although the association was only borderline significant; the association was non-significant for higher dietary $\mathrm{Ca}$ intake; no significant associations were found in men. The differences between postmenopausal women in the top and bottom quintiles of $\mathrm{Ca}$ intake do not provide an obvious explanation for the observed associations. These results confirm observations from previous studies, which have shown that the beneficial effect of soya on bone density is stronger in subjects with lower dietary Ca intake ${ }^{(30-32)}$. The mean $\mathrm{Ca}$ intake in cohort studies, which showed a positive association between soya intake and bone health, was below $650 \mathrm{mg} / \mathrm{d}$ in the Shanghai Women's Health Study ${ }^{(6)}$ and the Chinese and Japanese participants of the SWAN study ${ }^{(7)}$. These data suggest that with low $\mathrm{Ca}$ intake, soya intake can affect bone density; the strong association in populations with high habitual soya consumption, and the weak association in this cohort, also suggest a dose-response effect. However, there are still insufficient data available to explain this association.

The results in postmenopausal women clearly suggest an interaction between dietary $\mathrm{Ca}$, soya and bone density. Conversely, the results for men do not suggest such an interaction: enterolignans and equol were not associated with BUA, and no significant associations were observed after stratification for $\mathrm{Ca}$ intake.

The magnitude of the relationship observed (difference of adjusted means between the top and bottom quintiles of intake) was $1.5 \mathrm{~dB} / \mathrm{MHz}$ of BUA in men, and between $1 \cdot 2 \mathrm{~dB} / \mathrm{MHz}$ (for formononetin) and $2 \cdot 1 \mathrm{~dB} / \mathrm{MHz}$ (total phytooestrogens in the lowest quintile of $\mathrm{Ca}$ intake) in postmenopausal women. Although this estimate would be attenuated due to the random measurement error in dietary intake, it is of interest in terms of the physiological relationship between dietary phyto-oestrogen intake and BUA. A reduction of $1 \mathrm{SD}$ of BUA $(20 \mathrm{~dB} / \mathrm{MHz})$ is associated with about doubling in the risk of fracture ${ }^{(10)}$, so 2 units might be associated with a $10 \%$ difference in fracture risk.

In conclusion, our data indicate an independent association between the non-soya isoflavones formononetin and biochanin $\mathrm{A}$ and bone density in postmenopausal women and men, respectively. Positive associations observed for enterolignans and equol in postmenopausal women became nonsignificant following adjustment for $\mathrm{Ca}$ intake, and the likely explanation for most compounds is that these compounds act as a surrogate marker for $\mathrm{Ca}$. In postmenopausal women with low habitual Ca intake, soya isoflavones were borderline significantly associated with increased BUA in postmenopausal women, confirming reports from previous studies. Our results therefore suggest that non-soya isoflavones are associated with bone density independently of $\mathrm{Ca}$, whereas the association with soya or soya isoflavones is affected by dietary $\mathrm{Ca}$.

\section{Acknowledgements}

The present study was supported by the Medical Research Council, UK. The authors thank the EPIC-Norfolk study participants, general practitioners and study teams. The authors also acknowledge gratefully the support and expert advice by Dr Christina C. Dahm. The authors have no conflict of interest to declare. The authors' responsibilities were as follows: G. G. C. K. conducted the statistical analyses and wrote the manuscript; H. A. W. and A. V. conducted the statistical analyses and contributed to the manuscript; R. N. L., A. M. and N. G. F. contributed to the manuscript; K.-T. K. and N. J. W. (Principal Investigators of EPIC-Norfolk) contributed to the manuscript. 


\section{References}

1. Brynin R (2002) Soy and its isoflavones: a review of their effects on bone density. Altern Med Rev 7, 317-327.

2. Branca F \& Lorenzetti S (2005) Health effects of phytoestrogens. Forum Nutr 100-11.

3. Morito K, Hirose T, Kinjo J, et al. (2001) Interaction of phytoestrogens with estrogen receptors alpha and beta. Biol Pharm Bull 24, 351-356.

4. Setchell KD \& Lydeking-Olsen E (2003) Dietary phytoestrogens and their effect on bone: evidence from in vitro and in vivo, human observational, and dietary intervention studies. Am J Clin Nutr 78, Suppl. 3, 593S-609S.

5. Liu J, Ho SC, Su Y-X, et al. (2009) Effect of long-term intervention of soy isoflavones on bone mineral density in women: a meta-analysis of randomized controlled trials. Bone $\mathbf{4 4}$, 948-953.

6. Zhang X, Shu X-O, Li H, et al. (2005) Prospective cohort study of soy food consumption and risk of bone fracture among postmenopausal women. Arch Intern Med 165, $1890-1895$.

7. Greendale GA, FitzGerald G, Huang MH, et al. (2002) Dietary soy isoflavones and bone mineral density: results from the study of women's health across the nation. $A m J$ Epidemiol 155, 746-754.

8. Day N, Oakes S, Luben R, et al. (1999) EPIC-Norfolk: study design and characteristics of the cohort. European Prospective Investigation of Cancer. Br J Cancer 80, Suppl. 1, 95-103.

9. Welch A, Camus J, Dalzell N, et al. (2004) Broadband ultrasound attenuation (BUA) of the heel bone and its correlates in men and women in the EPIC-Norfolk cohort: a crosssectional population-based study. Osteoporos Int 15, 217-225.

10. Khaw KT, Reeve J, Luben R, et al. (2004) Prediction of total and hip fracture risk in men and women by quantitative ultrasound of the calcaneus: EPIC-Norfolk prospective population study. Lancet 363, 197-202.

11. Welch A, Bingham S, Camus J, et al. (2005) Calcaneum broadband ultrasound attenuation relates to vegetarian and omnivorous diets differently in men and women: an observation from the European Prospective Investigation into Cancer in Norfolk (EPIC-Norfolk) population study. Osteoporos Int 16, 590-596.

12. Welch AA, McTaggart A, Mulligan AA, et al. (2001) DINER (Data Into Nutrients for Epidemiological Research) - a new data-entry program for nutritional analysis in the EPIC-Norfolk cohort and the 7-day diary method. Public Health Nutr 4, 1253-1265.

13. Kuhnle GG, Dell'Aquila C, Aspinall SM, et al. (2008) Phytoestrogen content of foods of animal origin: dairy products, eggs, meat, fish, and seafood. J Agric Food Chem 56, 10099-10104.

14. Kuhnle GGC, Dell'Aquila C, Aspinall SM, et al. (2008) Phytoestrogen content of beverages, nuts, seeds, and oils. J Agric Food Chem 56, 7311-7315.

15. Kuhnle GGC, Dell'Aquila C, Aspinall SM, et al. (2009) Phytoestrogen content of cereals and cereal based foods. Nutr Cancer 61, 302-309.
16. Kuhnle GG, Dell'Aquila C, Aspinall SM, et al. (2009) Phytoestrogen content of fruits and vegetables commonly consumed in the UK based on LC-MS and ${ }^{13} \mathrm{C}$-labelled standards. Food Chem 116, 542-554.

17. Kuhnle GG, Dell'Aquila C, Low Y-L, et al. (2007) Extraction and quantification of phytoestrogens in food using automated SPE and LC/MS/MS. Anal Chem 79, 9234-9239.

18. Welch AA, Bingham SA, Reeve J, et al. (2007) More acidic dietary acid-base load is associated with reduced calcaneal broadband ultrasound attenuation in women but not in men: results from the EPIC-Norfolk cohort study. Am J Clin Nutr 85, 1134-1141.

19. Coxam V (2008) Phyto-oestrogens and bone health. Proc Nutr Soc 67, 184-195.

20. Ward HA \& Kuhnle GGC (2010) Phytoestrogen consumption and association with breast, prostate and colorectal cancer in EPIC Norfolk. Arch Biochem Biophys 501, $170-175$.

21. Moayyeri A, Kaptoge S, Dalzell N, et al. (2009) Is QUS or DXA better for predicting the 10-year absolute risk of fracture? J Bone Miner Res 24, 1319-1325.

22. Trimpou P, Bosaeus I, Bengtsson BA, et al. (2010) High correlation between quantitative ultrasound and DXA during 7-years of follow-up. Eur J Radiol 73, 360-364.

23. Keinan-Boker L, van Der Schouw YT, Grobbee DE, et al. (2004) Dietary phytoestrogens and breast cancer risk. Am J Clin Nutr 79, 282-288.

24. Cotterchio M, Boucher BA, Kreiger N, et al. (2008) Dietary phytoestrogen intake - lignans and isoflavones - and breast cancer risk (Canada). Cancer Causes Control 19 259-272.

25. Horn-Ross PL, John EM, Canchola AJ, et al. (2003) Phytoestrogen intake and endometrial cancer risk. J Natl Cancer Inst 95, 1158-1164.

26. Tsutsumi N (1995) Effect of coumestrol on bone metabolism in organ culture. Biol Pharm Bull 18, 1012-1015.

27. Webb AL \& McCullough ML (2005) Dietary lignans: potential role in cancer prevention. Nutr Cancer 51, 117-131.

28. Dawson-Hughes B (1998) Osteoporosis treatment and the calcium requirement. Am J Clin Nutr 67, 5-6.

29. New SA, Robins SP, Campbell MK, et al. (2000) Dietary influences on bone mass and bone metabolism: further evidence of a positive link between fruit and vegetable consumption and bone health? Am J Clin Nutr 71, 142-151.

30. Chen YM, Ho SC, Lam SS, et al. (2004) Beneficial effect of soy isoflavones on bone mineral content was modified by years since menopause, body weight, and calcium intake: a double-blind, randomized, controlled trial. Menopause 11, 246-241.

31. Wong WW, Lewis RD, Steinberg FM, et al. (2009) Soy isoflavone supplementation and bone mineral density in menopausal women: a $2-y$ multicenter clinical trial. Am J Clin Nutr 90, 1433-1439.

32. Alekel DL, Van Loan MD, Koehler KJ, et al. (2010) The soy isoflavones for reducing bone loss (SIRBL) study: a 3-y randomized controlled trial in postmenopausal women. Am J Clin Nutr 91, 218-230. 